\title{
Criteria for determining an optimal cigarette tax: the economist's perspective
}

\author{
Kenneth E Warner, Frank J Chaloupka, Philip J Cook, Willard G Manning, Joseph P \\ Newhouse, Thomas E Novotny, Thomas C Schelling, Joy Townsend
}

\begin{abstract}
In the debate on cigarette taxation, both supporters and opponents of higher taxes often appeal to economic theory and analysis. To evaluate the criteria for defining an optimal cigarette excise tax from the perspective of economics, the Office on Smoking and Health of the US Centers for Disease Control and Prevention convened a meeting of economists on 5 May 1995. Meeting participants acknowledged that, by itself, neither the discipline of economics nor any other could determine what is socially "right" or "wrong". However, the economist's understanding of efficiency and equity in the workings of the marketplace can inform the debate, offering insights relevant to assessing the merits of tax proposals and of arguments supporting or opposing such proposals. In this paper, the efficiency and equity considerations that economists use in evaluating the desirability of a tax are described and applied to the case of cigarettes. It is concluded that at present neither the arguments of tax increase advocates nor those of opponents are well grounded in economic analysis per se. Additional research based knowledge of the costs imposed on people other than the immediate consumers of cigarettes, especially those related to environmental tobacco smoke, is needed, as is further understanding of children's responsiveness to cigarette price changes. Protection of children constitutes the strongest argument favouring increased taxation of cigarettes.
\end{abstract}

(Tobacco Control 1995; 4 : 380-386)

Keywords: cigarettes; taxation; economics

\section{Introduction}

1993-94 witnessed a lively debate on the desirability of substantially increasing the federal cigarette excise tax in the United States. Although political considerations undoubtedly predominated, the debate was marked by an unusual emphasis on economic theory and analysis. A controversial report by the Congressional Research Service concluded that there was no good justification for a tax increase, based on published economic and epidemiological analysis. ${ }^{1}$ At a congressional hearing, an economist representing the Tobacco Institute cited this report and the work of three prominent economists, Willard Manning, Joseph Newhouse, and Thomas Schelling, as opposing a tax increase. Specifically, he said that "Every one of these people who carefully appl[ies] economic methodology to the issue of taxing smoking come[s] to one simple conclusion: the tax is already too high."

At the core of the conceptual argument against increasing the tax is the notion that an excise tax ought to be set to cover the "negative externalities" created by the product or activity in question. Negative externalities are costs imposed on people other than the immediate consumers of the goods or service. The essence of the economic argument against increasing the tax was that the existing tax already covered external costs, as they had been estimated in previous research. ${ }^{1}$

Although theoretically inclined opponents of a tax increase focused on this specific issue, economists recognise that many other economic and behavioural considerations go into determining the optimal tax (if any) on a specific product or service. To evaluate the criteria for defining an optimal cigarette tax, from the perspective of the discipline of economics, the Office on Smoking and Health of the US Centers for Disease Control and Prevention convened a meeting of economists in Boston, Massachusetts, on 5 May 1995. The group included the three prominent economists cited by the Tobacco Institute as well as others with expertise in the economics of tobacco or in the evaluation of social costs. ${ }^{\text {a }}$ This report summarises the group's conclusions about appropriate principles of taxation, their application to cigarettes, and associated needs for additional research.

We recognised at the outset that there are several different reasons for raising cigarette excise taxes, including (1) the need to raise revenue; $(2)$ the belief that smokers should pay for the burden they impose on others; (3) the desire to protect children, who may have a poor appreciation of both risk and addiction and a tendency to undervalue the future; and (4) the objective of improving public health.

" One of us (TEN), a physician, was the one noneconomist participant. He has engaged in research on the medical costs of smoking, including an important recent analysis. ${ }^{3}$ 
We acknowledged that, by itself, neither our discipline of economics nor any other could determine what is socially "right" or "wrong". However, the economist's understanding of efficiency and equity in the workings of the market place can inform the debate, offering insights relevant to each of the four reasons given for increasing excise tax. In particular, this understanding can be used to evaluate the argument espoused by the tobacco industry, namely that economic theory and analysis fail to support an increase in the cigarette excise tax. ${ }^{\mathrm{b}}$

\section{Economic principles of taxation and} their application to cigarettes

From an economist's perspective, two categories of concern must be considered in seeking optimal taxation: efficiency and equity. We consider two principles pertaining to each and, in each case, examine its relevance to the debate on cigarette taxation.

\section{EFFICIENCY}

Minimising distortion of consumer choice

A fundamental premise of efficiency in taxation is that revenue should be raised in a manner that minimises distortions in consumers' choices among alternative goods and services and in their decisions of how much to consume or save. If one is using consumption taxes, the Ramsey Rule states that tax rates should vary inversely with the elasticity of demand for products (holding the elasticity of supply constant). Elasticity of demand is a measure of the relative responsiveness of demand to price changes, defined as the percentage change in quantity demanded induced by a one per cent change in price. Therefore, the Ramsey Rule means that goods for which consumers' demand is least affected by price changes should bear the highest taxes. This will minimise consumers' loss of utility (loosely defined as satisfaction) associated with a tax causing them to forego consumption they would prefer in order to avoid paying the tax.

Consistent with the Ramsey Rule, cigarettes appear to be excellent targets for sizeable product specific taxation. Cigarettes are widely regarded as having a relatively low elasticity of demand, with a consensus estimate in the vicinity of -0.4 in many of the major industrialised nations. ${ }^{4}$ Hence cigarette taxes are perceived to be efficient revenue generators, with a $1 \%$ increase in the tax rate generating about a $0.9 \%$ increase in revenue. ${ }^{5}$

The efficiency of cigarette taxes as a revenue generator has been questioned recently, with

b The principles espoused in the paper apply equally to taxation of other tobacco products, in addition to cigarettes. However, given the predominance of cigarette smoking among tobacco users in the USA and other industrialised nations, the wealth of data pertaining to smoking, and the interest in the cigarette excise tax, this paper focuses explicitly and exclusively on cigarette taxation. Similarly, the paper considers only a federal excise tax, although once again, the same principles would apply at the state or local level. research using a new model of consumer demand that includes addiction as a factor, concluding that the long run elasticity of demand for cigarettes may be twice the short run elasticity, and therefore possibly twice as high as earlier estimates. ${ }^{6}$ Although this research is far from definitive, it raises the possibility that the long run revenue estimates projected for cigarette tax increases may be too high. ${ }^{\circ}$

Resolving the debate about the long run elasticity is important for two reasons. In addition to producing accurate estimates of revenue, the public health benefits of tax increases hinge on the elasticities. The health and revenue benefits of taxation are inversely related: a very low elasticity would mean that cigarette taxation is an efficient revenue generator, but because it would represent little change in smoking in response to increased taxes, the health gain anticipated by the public health community would be small. In contrast, if the elasticity is higher, the revenue potential of a tax increase would be more limited but the health gain would be more substantial.

Although the efficiency of the cigarette tax has been called into question, ${ }^{7}$ this dimension of the tax debate has focused more on degree rather than kind (that is, how high should the tax be raised, if it is raised at all). Little disagreement exists that an increase in the tax rate would generate significant increases in revenue, or that it would decrease consumption.

\section{Bearing the cost of consumption decisions}

A second efficiency condition, central to the conceptual debate on cigarette taxation, is that individuals should bear the full costs of their consumption decisions; their consumption of a product should not impose (uncompensated) costs on other people. In essence, the full social cost produced by consuming the product should be reflected in the price paid by the immediate consumers. When social costs exceed consumers' direct costs, negative externalities result; others are forced to bear some of the burden of the consumption decision. This situation may justify the imposition of excise taxes equal to the difference between the total social cost and the (tax-free) price paid by the consumer. (A divergence between social and private costs also has fairness implications, as discussed below.)

Estimation of the negative externalities produced by smoking is a hotly contested efficiency issue in the cigarette tax debate. Two issues are of paramount concern: (1) the extent of the financial externalities associated with smoking due to the burden of smokers' smoking related diseases on taxpayers; and (2) the

c Discussions of the long run effects of tax increases, on both revenues and consumption, are generally based on the real value of the tax increase being sustained over time. Because the vast majority of cigarette taxes in the USA are imposed in nominal terms, inflation erodes the real value of the nominal tax increase from one year to the next. 
burden of environmental tobacco smoke on the non-smoking population.

The first of these lies at the core of the "user fee" argument for cigarette taxation. Smokers, it is argued, will use publicly provided medical care resources to pay for their smoking induced illnesses, in the United States primarily through the Medicare and Medicaid programmes. Tax proponents say that smokers should cover these extra costs through excise taxes imposed on the cigarettes that cause the disease burden.

However appealing this argument may seem to be, it has significant limitations. First is the matter of timing: the burden that cigarettes consumed today will impose on current smokers will not be realised until the often distant future. For many contemporary smokers, the burden will be small, since they will stop smoking before the behaviour has produced its most significant health damage. But even for smokers who will continue to smoke throughout their lives, the issue of timing has two important implications for the financial externality argument, one relatively easy to handle conceptually, the other far more difficult. The easy one relates to the need to discount future costs to equate them to their present value, reflecting the fact that future dollars (pounds, etc) are valued less highly than present dollars. ${ }^{8}$ More challenging is that estimation of the theoretically appropriate tax to cover these costs requires a quite sophisticated estimation of future smoking related health care and other related costs. These, in turn, depend on both the technology of medicine in the future - will there, for example, be a cure for lung cancer? - and the costs of procedures in that future. Use of today's smoking related health care costs as a proxy for those that will be experienced by today's smokers is therefore imperfect.

The second limitation, emphasised in evaluations of the financial externality in the United States, ${ }^{1,9}$ is that precisely because smokers die younger on average than non-smokers, the former receive smaller social security payments and experience a briefer period of eligibility for Medicare services than the latter. In effect, smokers subsidise non-smokers' social security payments ${ }^{\mathrm{d}}{ }^{10,11}$

This observation may not hold in all countries and under all circumstances. For example, analysis in the United Kingdom concluded that higher sickness benefits paid to smokers and pensions paid to their dependents compensated for the lower direct pension benefits paid to smokers as a consequence of their earlier average age of death. ${ }^{13}$ Similarly, the observation would not be valid in developing countries in which health care is subsidised but responsibility for old age

\footnotetext{
d The extent to which smokers subsidise nonsmokers' Medicare expenditures is unclear. An analysis by Hodgson concluded that males who had ever smoked consume more Medicare resources than those who had never smoked, despite the fact that the latter live longer into the Medicare years. ${ }^{12}$
}

expenses is a private matter. Furthermore, for the United States and other countries, projections of the future implications of smoking for social security payments depend on the future structure of the system, much as the costs of future smoking related illnesses will depend on the technology of the day.

These qualifications notwithstanding, the mere suggestion that smokers may subsidise non-smokers' social security benefits has created a furor, with the tobacco control community arguing that it is absurd to value death as an economically desirable event and that counting this financial benefit without attributing any positive value to life or good health per se means that society should never engage in activities that prolong life beyond workers' productive years.

This response confuses two separate issues. One is the failure of analyses of the costs and benefits of smoking to attribute a value to life per se. Although true, this is not relevant to the task at hand, namely, the appropriate response to the user fee basis for cigarette excise taxation. The other issue does concern the appropriate response, however. As long as that basis is the excess financial burden that smokers impose on the public sector, including the Medicare and Medicaid systems in the United States, from this purely fiscal perspective smokers should receive a "credit" for their social security savings. This is independent of the value of life per se.

If one accepts this logic, the user fee basis for increased cigarette excise taxation seems limited, and careful economic analyses have suggested that smokers may well have been "paying their own way" on this criterion as it is applied to financial externalities. ${ }^{9}$ This conclusion does not address the totality of the negative externality issue, however. Herein lies a major point of empirical contention in the literature: does smoking impose costs on non-smokers, other than the financial externalities just discussed, that warrant increasing cigarette excise taxes? The issue is the health and associated economic effects of environmental tobacco smoke.

Estimates of the costs of environmental tobacco smoke vary dramatically, with the most prominent study finding them to be relatively modest, although this analysis limited consideration to the effects of environmental tobacco smoke on low birthweight and cancer, ${ }^{9}$ and a more recent analysis concluding that they are substantial. ${ }^{14}$ In part, the differences reflect varying interpretations of the underlying epidemiology, and indeed developments in the epidemiological evidence over the period during which such studies have been performed. Recent research provides strong evidence that the mortality toll associated with environmental tobacco smoke may be more than an order of magnitude larger than that associated with lung cancer, primarily reflecting heart disease mortality now associated with environmental tobacco smoke, ${ }^{15,16}$ but previous economic studies have not included environmental tobacco smoke related heart disease. In addition, earlier

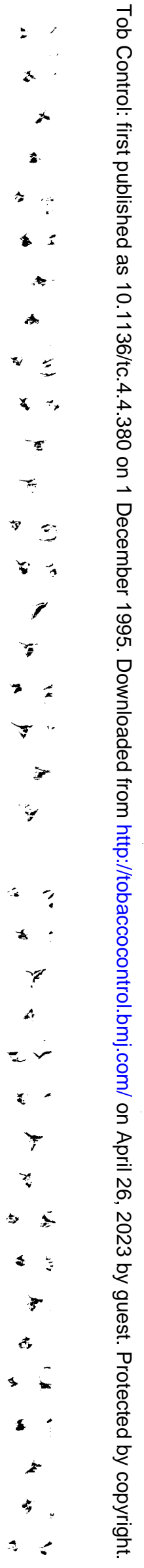

$s$ 
studies failed to account for the perinatal effects of smoking by pregnant women.

Although the precise burden of environmental tobacco smoke remains a matter of some debate, epidemiologists have little doubt that the mortality burden greatly exceeds the cancer toll alone. Clearly, economic analyses incorporating more recent estimates of the health consequences of environmental tobacco smoke would generate higher estimates of the external costs of smoking than those found in earlier reports. The economic analyses, however, face empirical and conceptual challenges beyond selecting an estimate of the health burden of environmental tobacco smoke. For example, how much value should be placed on the life-years lost due to environmental tobacco smoke? Both the methods of valuing life-years and the specific application in this case present analytical problems. ${ }^{17}$

Similarly, economic analysts must determine what to evaluate as an external cost of environmental tobacco smoke and what to consider an internal cost. Economics typically considers the family as the economic decision making unit. Thus smoking by a husband that results in his non-smoking wife's lung cancer would be treated as a cost, or consequence, internal to the consumption decision making unit; it would not be considered an externality. As such, the relevant environmental tobacco smoke mortality toll would be that which occurs outside of the family, in workplaces for example. (Economists have not explicitly addressed the implications of ignorance of the health effects of environmental tobacco smoke in this context. Certainly, most of the environmental tobacco smoke related lung cancers experienced to date have resulted from exposures predating public understanding of its consequences.)

Although most economists would accept treatment of the health of spouses as an internal cost, many would be reluctant to apply it universally to fetuses and children. Although children are certainly members of the "consuming unit," they are relatively powerless to affect consumption decisions that may influence their health, especially when they are very young. As such, one might conclude that society has a special interest in their welfare that makes adverse effects of environmental tobacco smoke a social cost.

Note that the financial externality that can arise from smoking related health care within a family remains a negative externality, to be included in estimates of social costs. Thus in the United States, if a woman contracts lung cancer as a result of her husband's smoking, hel Medicare or Medicaid related health care costs would constitute a negative externality of her husband's smoking. Those costs covered by the husband and wife privately would not be considered social costs under the conventional economist's framework for cost accounting.

The complexity of these issues led the economists meeting in Boston to recommend further research on the negative externalities associated with environmental tobacco smoke.
A component of such further research, yet to be mentioned here, is potentially of considerable consequence: how to identify and value the costs associated with environmental tobacco smoke. To date, only two types of costs have received much analytical attention: medical costs (the financial externalities of smokers' health care costs and the costs of environmental tobacco smoke related illnesses) and the value of lost productivity associated with smoking induced illness and premature mortality. A variety of additional costs has been considered but then ignored, the assumption being that their aggregate magnitude pales in comparison with the medical costs These include fire damage, additional costs of building ventilation necessitated by smoking, additional costs of cleaning clothes for nonsmokers who have been in smoke filled rooms, and so on.

At least one cost that has escaped attention could be substantial: the annoyance experienced by non-smokers subjected to smokey environments, independent of the adverse health consequences of environmental tobacco smoke. Suppose that the average non-smoker would pay $\$ 50$ per year to avoid the annoyance produced by cigarette smoke. ${ }^{e}$ With more than 210 million Americans being non-smokers, this would represent a collective willingness to pay $\$ 10.5$ billion to avoid the annoyance produced by environmental tobacco smoke in the United States. With smokers consuming roughly 25 billion packs of cigarettes per year, this would suggest that a tax of 42 cents per pack would be warranted simply to cover the annoyance costs of environmental tobacco smoke, independent of its health consequences. Note that unlike the future medical costs that would result from today's smoking, the annoyance cost is a present day cost attributable to present day smoking. ${ }^{p}$

The principal reason that no one has included the annoyance cost in calculations of

e If readers deem this figure high (or low), they can select a figure of their own and adjust the remaining numbers in this paragraph accordingly.

'As described here, non-smokers' annoyance associated with environmental smoke is interpreted as a cost imposed by smokers on nonsmokers and for which smokers should be responsible; hence the logic behind increasing the tax enough to cover the annoyance costs. This view presupposes that non-smokers have a right to clean air and that smokers should compensate them (through the government, which collects the tax) for fouling it. Theoretically, one can imagine a different interpretation of property rights in which smokers have the right to use the air as they see fit. In this instance, non-smokers' willingness to pay to avoid ETS would translate into their paying smokers not to foul the air (challenging questions of how the transfer would be effected notwithstanding). This conceptual distinction is of little practical value, primarily because in most societies that have contemplated the issue, the non-smokers' right to clean air predominates over the smokers' right to pollute the air. Witness the increasingly commonplace adoption of clean indoor air laws. 
the negative externalities associated with environmental tobacco smoke is the difficulty of measuring it. Economists agree that the willingness to pay to avoid some hazard, such as environmental tobacco smoke, is the conceptually appropriate measure of its value; but willingness to pay is notoriously hard to estimate. As a consequence, the tendency has been to use other measures, such as lost productivity, to value the more "tangible" losses associated with something like environmental tobacco smoke.

The annoyance factor associated with environmental tobacco smoke does not necessarily recommend higher taxes as the solution. Laws prohibiting smoking in public places and work places can address the annoyance factor more directly than can a tax increase. As such, perhaps the theoretically correct annoyance cost to include in estimates of the social costs of environmental tobacco smoke is that which clean indoor air laws do not prevent.

As this lengthy discussion should suggest, the issues surrounding identification and valuation of the negative externalities associated with direct smoking and with environmental tobacco smoke are numerous and complicated. All that we can conclude at present is that the social costs almost certainly exceed those that were estimated in the often cited but early attempt to value the negative externalities, ${ }^{9}$ possibly considerably. Further research will be required to determine to what extent.

\section{EQUITY}

Equity refers to the fairness of a tax, evaluated according to two principles: the benefit principle and the ability to pay principle.

\section{The benefit principle}

The benefit principle says that individuals should pay for government provided services in proportion to the benefit they derive from them. Common examples include motor fuel taxes and bridge and highway tolls, both dedicated to financing road construction and repair. In each case, drivers pay for driving related government services roughly according to their level of use.

The "user fee" notion applied to smoking, discussed above, represents the tax increase proponents' attempt to frame the issue in terms of benefit principle fairness. The objective is to use taxation to link smoking with the social costs others bear when smokers become sick. Most notably, since smokers consume publicly funded health care resources, advocates of a user fee approach to cigarette taxation argue that excise taxes should be imposed to force smokers to "pay their own way."

The user fee equity argument is inextricably tied to the efficiency issue of whether smokers impose negative externalities on non-smokers. Discussed in detail in the preceding section, this will not be pursued further here.
The ability to pay principle

The ability to pay principle says that citizens who are more able to pay for the costs of government ought to pay more in taxes than those who are less able to pay. The ability to pay principle has two dimensions. Horizontal equity means that people in equal circumstances should be treated equally, in this case taxed equally. Vertical equity means that people in different circumstances should be treated unequally in a fair manner; again, more affluent taxpayers should pay more of the tax burden than the less affluent.

Increasing cigarette taxes is often criticised on the grounds that cigarette taxation violates vertical equity because cigarette taxation is regressive (that is, poor individuals pay a higher proportion of their income in cigarette taxes than more affluent individuals). Questions about horizontal equity can be raised as well, because cigarette taxation has the effect of imposing more of the costs of government on people who are distinguished only by their decisions to spend some of their income on tobacco products.

Cigarette taxes would be regressive if poorer and more affluent consumers smoked at the same rate, because expenditures on cigarettes constitute a smaller share of the income of affluent consumers. However, the fact that the poor have a higher prevalence of smoking than the affluent exacerbates the problem of regressivity. (This assumes, of course, that the higher prevalence is proportionately larger than a lower daily consumption, if the latter characterises smoking by poorer consumers.)

Although a given cigarette tax may be regressive, the degree of the regressivity of an increase in the tax is not obvious. Evidence in the United Kingdom suggests that price elasticity of demand for cigarettes is inversely correlated with social class, with the lower social classes - those with the highest smoking prevalence-having an elasticity of approximately 1.0 and the highest social classes having a very small elasticity. ${ }^{18}$ Under such circumstances, depending on the relative consumption levels of the different classes, an increase in the tax might redistribute the relative burden in a progressive manner. Given the correlation between income and education, the British data are supported by an analysis of US data that found that less educated smokers are more price responsive than more educated smokers. ${ }^{19}$

If the tax burden consequences of a tax increase are uncertain, the health implications are not. Precisely because proportionately more poor people than affluent people smoke, and because the former may be more responsive to tax induced price changes, one certain outcome of a cigarette tax increase would be a distribution of the resulting health benefit that favours the poor. The poor currently bear a disproportionate share of the health burden of smoking. ${ }^{18}$ Consequently, tax induced quitting (or avoidance of initiation of smoking) will diminish the socioeconomic gap in the disease burden of smoking.

Most economists, including meeting partici- 
pants, would view this distributional benefit of taxation as irrelevant to the issue of tax equity, concluding that it smacks of paternalism. We pursue this notion indirectly in the following section, which addresses the implications of nicotine addiction for economic analysis.

In closing this section, it is important to note that although economists prefer that individual taxes satisfy the ability to pay principle, concern focuses typically on the net effects of the overall tax system, combined with the redistributional effects of the expenditure side of government. That is, the foremost goal is to produce a tax and expenditure system that, collectively, is progressive. This is important to recognise because individual efficiency and equity goals can conflict with one another in evaluating optimal cigarette taxation, with vertical equity often at issue. Equity principles can conflict with each other; for example, benefit principle taxation (the "user fee") can lead to a distribution of tax burden that violates vertical equity, imposing higher taxes on persons less able to pay. Similarly, principles of equity and efficiency can conflict; for example, negative externalities may appear to justify higher taxes on cigarettes, but such taxes may be regressive, imposing a disproportionate burden on those least able to pay.

\section{A FINAL PRINCIPLE WITH EQUITY AND} EFFICIENCY RAMIFICATIONS

One final principle normally goes unstated, primarily because economists take it for granted; it underlies all microeconomic analysis. We state it here explicitly due to its importance to the analysis of cigarette taxation: consumption decisions are assumed to be the product of informed, rational choice by mature individuals.

The two key features of smoking that, together, violate this assumption are the fact that nicotine is addictive and that the onset of nicotine addiction occurs primarily during childhood. ${ }^{4}$ Although one can debate whether addiction per se violates the assumption of informed rational choice, ${ }^{6}$ even hardened libertarians would concur that children deserve guidance in making their consumption decisions regarding dangerous addictive drugs. Where libertarians and others might part company, however, is in the role of the state (government) in providing such guidance.

Our group of economists concluded that protecting children constitutes the strongest argument favouring increased taxation of cigarettes. Particularly given the inducements to use such products in children's everyday environment, including tobacco industry advertising and promotion totaling $\$ 6$ billion per year in the United States alone, ${ }^{20}$ we deem government intervention to help "balance" the environment to be warranted.

Support for increased taxation as a means of balancing the environment followed a consideration of the two problems associated with smoking by children: (1) their frequent failure to appreciate the risks associated with the behaviour, combined with their under- estimating the likelihood that initiation of smoking will lead to long term nicotine dependence; and (2) their tendency to "discount" the future heavily, that is, to be oriented primarily, if not exclusively, to the immediate present, in a manner that, as rational adults, they might come to regret.

In principle, measures such as public education targeting children and restrictions on underage purchases address the knowledge problems directly; we support such measures, although with recognition that, in practice, they have shown limited effectiveness. ${ }^{4}$ These measures do not address the second issue, however - namely, the tendency of children to heavily discount the future. Taxation is perhaps the best policy instrument to address this problem, both conceptually and empirically.

Taxation is a rather blunt instrument, in that a large majority of the burden of any tax increase will be born by adult smokers, not children. Taxation has been shown to be an effective deterrent to smoking, however, with the preponderance of evidence suggesting that this is especially true among children, ${ }^{21}$ and even many smoking adults support tax increases with the expectation that they will discourage children from initiating nicotine addictions. ${ }^{22}$ (More generally, taxation seems to be most effective as a deterrent to smoking among groups of people for whom education has been least effective. ${ }^{18}$ ) As such, we deemed increased taxation a reasonable component of a package of policy measures directed at discouraging smoking by children.

\section{Conclusions and recommendations}

We concluded that neither the arguments of tax increase advocates nor those of opponents are well grounded in economic analysis per se. In particular, advocates' support of the user fee notion has serious limitations, both conceptual and empirical; and opponents' conclusion that externalities are not sufficient to warrant higher taxes is based on old and incomplete analysis.

If economics is to make useful contributions to the ongoing debate about the desirable level of cigarette taxation, several unresolved issues deserve further attention. ${ }^{23.24}$ Specifically, we recommend in the USA that the Office on Smoking and Health support research directed at the numerous and complicated questions discussed above that pertain to estimation of the negative externalities associated with smoking, especially those related to environmental tobacco smoke. Research already under way on children's responsiveness to cigarette price changes and additional work on the new addiction model of consumer demand should also provide useful input into further consideration of optimal taxation. Finally, we noted subtle issues that might warrant further research as well. For example, do higher taxes encourage smokers to switch from higher priced branded cigarettes to lower priced (and often higher tar and nicotine) generic and discounted brands, thereby possibly increasing 
smokers' exposure to the toxic substances in cigarette smoke ${ }^{25}$ What would be the net health impact of tax induced quitting and tax induced switching?

At our meeting, we considered a broad array of arguments used to support increased taxation on economic grounds, ranging from revenue raising efficiency to health implications. Concerning the latter, we concluded that a focal point of debate, externalities, might recommend higher taxes, recognising the newer epidemiological evidence on the adverse health consequences of environmental tobacco smoke and considering the issue of nonsmokers' willingness to pay to avoid this hazard. Uncertainty about the implications of externalities led to the recommendation for further research. We also concluded that the value of increased taxation in discouraging children from becoming addicted to nicotine was potentially the most powerful argument supporting increased taxes.

We acknowledged other considerations favouring tax increases that, as economists, we cannot address with any special professional expertise. We acknowledged the legitimacy of society's adopting a public health stance on the matter through the political process. ${ }^{\mathrm{g}}$ For the United States, we reviewed data that found cigarette taxes low in real terms both relative to the tax's history within the United States and compared with the contemporary tax rates found in most of the world's major industrialised nations. ${ }^{21}$

A principal conclusion of the meeting was that economic analysis can inform but never resolve the debate on how much society should tax cigarettes. We recognised that in developing our own personal positions on whether the tax should be increased, we have been swayed in part by considerations other than those that derive from our professional expertise as economists. For example, each of the three economists cited by the Tobacco Institute as having produced work that effectively opposes a tax increase has stated that, for a variety of reasons, not all economic, he supports a substantial increase in the federal cigarette excise tax in the USA.

g A public health perspective would accord explicit social value to increased longevity resulting from taxation. From the perspective of traditional economics, additional life-years gained as a result of tax induced quitting (or noninitiation of smoking) are viewed as a private benefit, accruing to the individual who gains the years and to his or her family. Under the public health perspective, the value of additional lifeyears gained would constitute a benefit in a social benefit-cost calculus used to evaluate the desirability of the policy intervention. Being public health professionals as well as economists, some of the authors believe that this public health perspective is an appropriate one for matters of policy making in the public health arena. As the purpose of this analysis was to employ the traditional tenets of the economics profession, however, we have adhered strictly to that perspective in the evaluation presented in this paper.
Dr Jeffrey Harris also participated in the meeting from which this article is derived. Because Dr Harris has some fundamental disagreements with the traditional economic perspective, as expressed in this report, he did not wish to participate in the paper as an author. We are indebted to him for his in the comments during the meeting anded to him for his helpful comments during the meeting and on a draft of this paper. We
also thank the Office on Smoking and Health (OSH) of the National Center for Chronic Disease Prevention and Health Promotion, Centers for Disease Control and Prevention, and especially the Director of OSH, Dr Michael Eriksen, for organising the meeting from which this report is derived. We wish to emphasise that this paper does not necessarily represen the opinions or conclusions of the Office, however. Responsibility for all of the material in this report rests exclusively with the authors.

1 Congressional Research Service. Cigarette taxes to fund health care reform: an economic analysis. Washington, DC: Congressional Research Service, Library of Con gress, 1994.

2 Committee on Finance, United States Senate. Tax treatment of organizations providing health care services, and excise taxes on tobacco, guns and ammunition. Hearing, April 28 , 1994. Washington, DC: US Government Printing Office, 1994: 40.

3 US Centers for Disease Control and Prevention. Medical care expenditures attributable to cigarette smoking United States, 1993. MMWR 1994; 43: 469-72.

4 US Department of Health and Human Services. Preventing tobacco use among young people. A report of the Surgeon General. Atlanta, Georgia: Public Health Service, Centers for Disease Control and Prevention, Office on Smoking and Health, 1994. (US Government Printing Smoking and Health, 1994. (US
Office No S/N 017-001-00491-0.)

5 Jones A, Posnett J. The revenue and welfare effects of cigarette taxes. Applied Econ 1988; 20:1223-32.

6 Becker GS, Grossman M, Murphy KM. An empirical analysis of cigarette addiction. Am Econ Rev 1994; 84 396-418.

7 Becker GS, Grossman M. ...And cigarette revenues up in smoke. Wall Street F 1994, August 9: A12.

8 Warner KE, Luce BR. Cost-benefit and cost-effectiveness analysis in health care: principles, practice, and potential. Ann Arbor, Michigan: Health Administration Press, 1982

9 Manning WG, Keeler EB, Newhouse JP, Sloss EM, Wasserman J. The taxes of sin: do smokers and drinkers pay their way? $\mathcal{J} A M A 1989 ; 261: 1604-9$

10 Shoven JB, Sundberg JO, Bunker JP. The Social Security cost of smoking. In: Wise DA, ed. The economics of aging. Chicago, Illinois: University of Chicago Press, 1989 $231-50$.

11 Viscusi WK. Cigarette taxation and the social consequences of smoking. In: Poterba JM, ed. Tax policy and the economy. Cambridge, Massachusetts: Massachusetts Institute of Technology Press, 1995: 51-101.

12 Hodgson TA. Cigarette smoking and lifetime medical expenditures. Milbank $Q$ 1992; 70: 81-126.

13 Atkinson $\mathrm{AB}$, Townsend JL. Economic aspects of reduced smoking. Lancet 1977; ii : 492-5.

14 US Environmental Protection Agency. The costs and benefits of smoking restrictions: an assessment of the smoke-free environment act of 1993 (H.R. 3434). Indoor Air Division, Office of Radiation and Indoor Air. Washington, DC: US Environmental Protection Agency, April 1994 15 Steenland $\mathrm{K}$. Passive smoking and the risk of heart disease.
fAMA 1992; 267: 94-9.

16 Glantz SA, Parmley WW. Passive smoking the heart disease: mechanisms and risk. $\mathcal{F A M A} 1995 ; 273$ : 1047-53.

17 Viscusi WK. The value of risks to life and health. $\mathcal{F}$ Econ Lit $1993 ; 31: 1912-46$.

18 Townsend J, Roderick P, Cooper J. Cigarette smoking by socioeconomic group, sex, and age: effects of price, socioeconomic group, sex, and age: effects of price,
income, and health policy. $B M \mathcal{F}$ 1994; 309: 923-7.

19 Chaloupka FJ. Rational addictive behavior and cigarette smoking. $\mathcal{F}$ Polit Econ 1991; 99: 722-42.

20 Cigarette advertising and promotion in the United States, 1993: a report of the Federal Trade Commission. Tobacco Control 1995; 4: 310-3.

21 Chaloupka FJ. The economics of tobacco. Working paper, Department of Economics, University of Illinois at Chicago, 1995

2 Highlights from an American Cancer Society survey of US voters' attitudes toward cigarette smoking. Boston, Massachusetts: Marttila \& Kiley, Inc, 1994

23 Sweanor D, Ballin S, Corcoran RD, Davis A, et al. Report of the tobacco policy research study group on tobacco pricing and taxation in the United States. Tobacco Control pricing and taxation in the

24 The impact of cigarette excise taxes on smoking among children and adults : summary report of a National Cancer Institute axd adults: summary report of a National Cancer Institute expert panel. Bethesda, Maryland: Cancer Control Sci-
ence Program, Division of Cancer Prevention and ence Program, Division of Cancer Prevention
Control, National Cancer Institute, August 1993.

25 Evans WN, Farrelly MC. The compensating behavior of smokers: taxes, tar and nicotine. Working paper, Department of Economics, University of Maryland, 1995.
$+$ 